Check for updates

Cite this: RSC Adv., 2019, 9, 29327

Received 26th July 2019

Accepted 2nd September 2019

DOI: $10.1039 / c 9 r a 05806 k$

rsc.li/rsc-advances

\section{One-step solution synthesis of a two-dimensional semiconducting covalent organometallic nanosheet via the condensation of boronic acid $\dagger$}

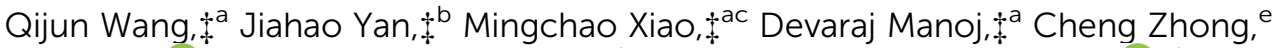 \\ Qiying Lv, (iD ${ }^{a}$ Lite Yang, ${ }^{a}$ Liangmei Wu, ${ }^{\mathrm{b}}$ Zhuoping Wang, ${ }^{\mathrm{a}}$ Lihong Bao, (iD *b \\ Hongjun Gao, (D) ${ }^{b}$ Fei Xiao, ${ }^{a}$ Lang Jiang (D) c and Shuai Wang (D) *ad
}

In this work, a 2D covalent organometallic nanosheet (COMS) was designed and successfully synthesized through the one-step conjunction of a terpyridine-metal-terpyridine (TMT) sandwich coordinate motif with borate ester covalent heterocyclic $\left(\mathrm{B}_{3} \mathrm{O}_{3}\right)$ linkage via the condensation of boronic acid. The obtained 2D COMS with a cobalt coordination center (2D COMS-Co) showed promising p-type semiconducting properties.
Two-dimensional (2D) metal-organic frameworks (MOFs) obtained by using the strong bonding effects between metal ions and organic molecule species have aroused great interest; ${ }^{1-8}$ these include coordination nanosheets, which are a class of 2D materials featuring metal complex motifs. ${ }^{9-12}$ Covalent bonds are considered to be an effective way to fabricate covalent organic frameworks (COFs) such as COF-1, which is mainly constructed by a phenyl ring and borate ester to form covalent heterocyclic $\left(\mathrm{B}_{3} \mathrm{O}_{3}\right)$ linkage. ${ }^{13-15}$ Based on the synergistic effects of metal coordination and covalent interactions, Jiang and coworkers demonstrated the important role of central metals in controlling $\pi$-electronic functions through Mpc-COF. ${ }^{16}$ Nevertheless, the coordination bond forms spontaneously within the ring of the porphyrin heterocycle and not as the linkage between organic components. In addition, the connections made between metal ions and ligand motifs cannot facilitate the proper tuning of the physicochemical properties of the structure. ${ }^{17}$ Combining the covalent and coordinate features may provide an opportunity to design new 2D materials and thus, the synergetic enhancement in many unique properties can be achieved. As far as we know, the fabrication of $2 \mathrm{D} \mathrm{sem-}$ iconducting materials that combine the covalent heterocyclic

${ }^{a}$ School of Chemistry and Chemical Engineering, Huazhong University of Science \& Technology, Wuhan, 430074, P. R. China. E-mail: chmsamuel@mail.hust.edu.cn ${ }^{b}$ Institute of Physics, Chinese Academy of Sciences, Beijing 100190, P. R. China. E-mail: lhbao@iphy.ac.cn

'Institute of Chemistry, Chinese Academy of Sciences, Beijing 100190, P. R. China

${ }^{d}$ Department of Materials Science, Fudan University, Shanghai, 200433, P. R. China ${ }^{e}$ College of Chemistry and Molecular Sciences, Wuhan University, Wuhan, 430072, P. R. China

$\dagger$ Electronic supplementary information (ESI) available: Experimental details and additional data. See DOI: $10.1039 / \mathrm{c} 9 \mathrm{ra} 05806 \mathrm{k}$

$\$$ These authors are contributed equally to this work. linkage and coordinate linkage has not been reported. Therefore, it is a pressing need to construct a functional 2D organic framework through a one-step synthesis strategy, which would be a more attractive approach.

Herein, we first proposed an efficient one-step strategy to synthesize a 2D material by the synergy of covalent and organometallic interactions; it was named as a covalent organometallic nanosheet (2D COMS-M, M = cobalt (Co)). The asproposed 2D COMS-Co was constructed by linking the borate ester covalent heterocyclic $\left(\mathrm{B}_{3} \mathrm{O}_{3}\right)$ structure and terpyridine (tpy) metal coordination motif (TMT) (Fig. 1).

a

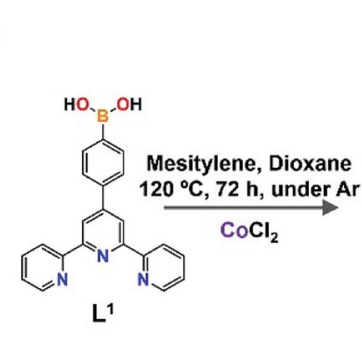

b
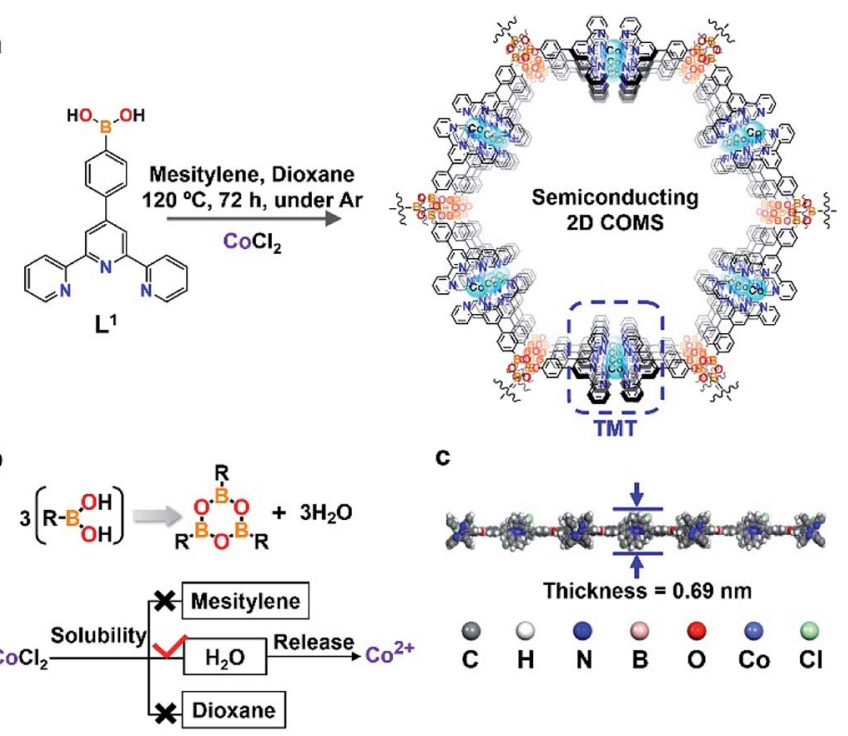

c

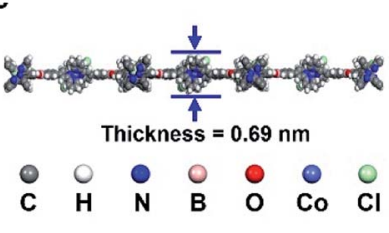

Fig. 1 (a) Synthesis route of the semiconducting 2D COMS. (b) Design principles of COMS via the condensation of boronic acid. (c) The calculated cross-sectional view of 2D COMS-Co. 
In order to explore the extended construction of 2D COMS, the self-condensation ligand 4-phenylborate- $2,2^{\prime} ; 6^{\prime}, 2^{\prime \prime}$-terpyridine $\left(\mathrm{L}^{1}\right)$ integrated with $\mathrm{CoCl}_{2}$ as the $\mathrm{Co}^{2+}$ carrier was employed through an anhydrous and oxygen-free hydrothermal reaction at $120{ }^{\circ} \mathrm{C}$ under argon, and the typical synthesis process is depicted in Fig. 1a (for details, please see ESI $\dagger$ ). Starting from the condensation reaction of boronic acid (Fig. 1b), $\mathrm{H}_{2} \mathrm{O}$ could be generated and played a key role in dissolving $\mathrm{CoCl}_{2}$ and further releasing $\mathrm{Co}^{2+}$ ions $\left(\mathrm{CoCl}_{2}\right.$ is practically insoluble in mesitylene and dioxane). This was followed by coordination between the terpyridine motifs and the released $\mathrm{Co}^{2+}$ ions to obtain 2D COMS. This novel strategy could achieve crystalline $2 \mathrm{D}$ materials by self-controlling the release of $\mathrm{Co}^{2+}$ through the one-step condensation reaction of boronic acid. The calculated cross-sectional view of 2D COMS-Co indicates that the thickness of the monolayer 2D COMS-Co is $0.69 \mathrm{~nm}$ (Fig. 1c). The dual synergistic connecting effects of covalence and coordination in 2D COMS-Co provided nanosheet-like morphology with significant improvement in the semiconducting performance. The hole mobility of the 2D COMSCo-based FET device could reach to $5.7 \times 10^{-5} \mathrm{~cm}^{2} \mathrm{~V}^{-1} \mathrm{~s}^{-1}$ with an ON-OFF ratio of 221, which demonstrated the potential application of 2D COMS-Co in semiconducting devices.

The scanning electron microscopy (SEM) image (Fig. 2a) reveals that $2 \mathrm{D}$ COMS-Co has a uniform micron-sized nanosheet-like structure. Furthermore, the transmission electron microscopy (TEM) image indicates that the as-synthesized 2D COMS-Co consists of few multi-layers. Fig. 2c shows an enlarged image of the selected area visualized with highresolution TEM (HRTEM), where the section enclosed by white lines depicts lattice fringes. Moreover, the selected area electron diffraction (SAED, inset of Fig. 2c) image shows a circular ring pattern that reveals the well-defined crystalline structure of 2D COMS-Co; these results are in agreement with our X-ray diffraction data (Fig. S2, ESI $\dagger$ ). Most interestingly, the atomic force microscopy (AFM) image (Fig. 2d) clearly demonstrates that the selected thickness of 2D COMS-Co is $2.07 \mathrm{~nm}$,

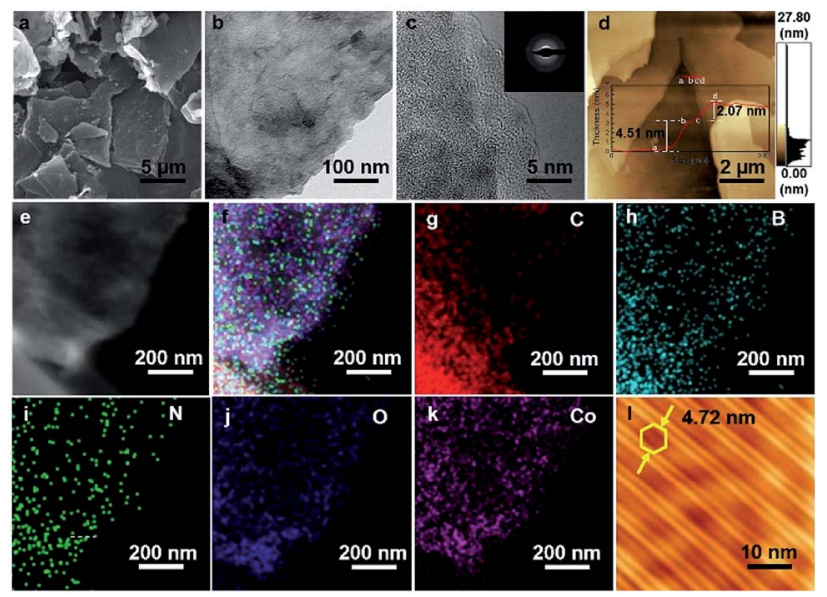

Fig. 2 Morphological characterization of 2D COMS-Co. (a) SEM image of powder. (b) TEM image. (c) HRTEM image (d) AFM image. (e) HAADF image. (f-k) STEM elemental mapping. (l) STM image. and the resultant thickness is three times less than the calculated value of $0.69 \mathrm{~nm}$ (Fig. 1c), indicating its uniform threelayer stacked structure. The above results collectively provide strong evidence of typical 2D features for COMS-Co. Moreover, the high-angle annular dark-field (HAADF) image and the scanning transmission electron microscopy (STEM) elemental mapping further revealed that the $\mathrm{C}$ (red), $\mathrm{B}$ (cyan), $\mathrm{N}$ (green), $\mathrm{O}$ (blue) and Co (pink) elements are homogeneously distributed on the selected area of 2D COMS-Co (Fig. 2e-k). The electronic structure of 2D COMS-Co was further characterized by fourprobe scanning tunnel microscopy (STM) (please see details in ESI†). The high-resolution STM imaging revealed that the 2D COMS-Co flake has a layered flake structure with uniformly distributed hexagonal hole morphology and the resultant holes have a diameter of $4.72 \mathrm{~nm}$ (Fig. 2l); this observation is in accordance with the proposed structure of 2D COMS-Co (Fig. S8, ESI $\dagger$ ).

Due to the covalence and coordination effects, the absorption peak of 2D COMS-Co obtained from the UV-vis measurements (Fig. 3a) is red-shifted in comparison to that for ligand $\mathrm{L}^{1}$, and the optical band gap is calculated to be $1.85 \mathrm{eV}$. Furthermore, density functional theory (DFT) calculations revealed that the highest occupied molecular orbital (HOMO) of $2 \mathrm{D}$ COMS-Co was dominated by the $\pi$ orbital of the $\mathrm{B}_{3} \mathrm{O}_{3}$ linkage and the phenyl ring, whereas the $\pi^{*}$ orbital of TMT was responsible for the lowest unoccupied molecular orbital (LUMO). Additionally, the calculated electronic band gap of 2D COMS-Co was $1.89 \mathrm{eV}$, which was in accordance with the optical band gap, confirming the successful synthesis of 2D COMS-Co. Fig. 3b displays the X-ray photoelectron spectroscopy (XPS) spectrum of 2D COMS-Co, in which the appearance of the binding energy peak at $192.2 \mathrm{eV}$ is significantly different from that for $\mathrm{L}^{1}(191.1 \mathrm{eV})$, which can be ascribed to the $-\mathrm{C}-\mathrm{B}-\mathrm{O}_{2}$
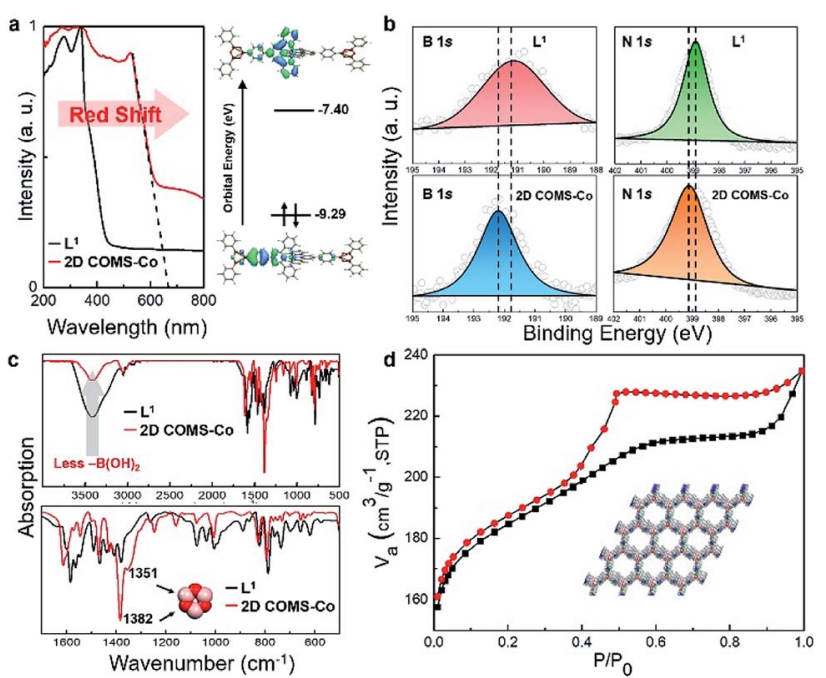

Fig. 3 (a) UV-vis spectra of $\mathrm{L}^{1}$ and 2D COMS-Co (left), electron distribution on $\mathrm{HOMO} / \mathrm{LUMO}$ and the orbital energy gap (right). (b) XPS $B$ 1s and $N$ 1s spectra of $L^{1}$ and 2D COMS-Co. (c) FT-IR spectra of $L^{1}$ and $2 \mathrm{D}$ COMS-Co. (d) $\mathrm{N}_{2}$ adsorption and desorption isotherms of $2 \mathrm{D}$ COMS-Co (inset: stacking porous view). 
structure. ${ }^{18,19}$ Compared to the observation for $\mathrm{L}^{1}$, the $\mathrm{N}$ 1s peak for 2D COMS-Co shifted to a higher binding energy value (399.2 $\mathrm{eV}$ for COMS-Co and $397.5 \mathrm{eV}$ for $\mathrm{L}^{1}$ ). The skewing of the peaks toward higher binding energy was induced by the contribution of $\mathrm{N}$ atoms in terpyridine to the metal center. Therefore, the XPS results clearly provide evidence of the existence of both covalent and coordination effects in the asprepared 2D COMS-Co. The Fourier transform infrared (FT-IR) spectra in Fig. 3c show that the $-\mathrm{B}(\mathrm{OH})_{2}$ bands (around $3500 \mathrm{~cm}^{-1}$ ) of the ligand $\mathrm{L}^{1}$ are significantly attenuated compared to that observed for 2D COMS-Co. In addition, the B-O stretching vibrations at $1351 \mathrm{~cm}^{-1}$ can be observed for $2 \mathrm{D}$ COMS-Co but not for $\mathrm{L}^{1}{ }^{13,20-22}$ Thus, the above results show that the expected $\mathrm{B}_{3} \mathrm{O}_{3}$ rings for 2D COMS-Co have indeed been formed. Notably, the nitrogen adsorption-desorption isotherms reveal that the Brunauer-Emmett-Teller (BET) specific surface area of 2D COMS-Co is as high as $598 \mathrm{~m}^{2} \mathrm{~g}^{-1}$ (Fig. 3d); it surpasses those of other layered materials, including the reported graphene oxide paper $\left(10 \mathrm{~m}^{2} \mathrm{~g}^{-1}\right)$, clays (10 to $100 \mathrm{~m}^{2}$ $\mathrm{g}^{-1}$ ), and pillared clays (50 to $300 \mathrm{~m}^{2} \mathrm{~g}^{-1}$ ), and is in the range of the values of the most porous zeolites and many porous carbons. ${ }^{13,23}$ This drastic enhancement can be assigned to the uniform porous structure of the as-synthesized 2D COMS-Co.

The above results show that the 2D COMS-Co units arranged in periodic strips can provide conducting pathways for charge carrier transport through TMT and central cobalt ions. 2D COMS-Co was employed to function as the active semiconducting channel in a field-effect transistor (FET) device. As shown in Fig. 4a, the individual 2D COMS-Co sample is deposited on an $\mathrm{Si}$ wafer as the semiconducting layer to construct the FET device. The 2D COMS-Co-based FET device delivered hole mobility of $5.7 \times 10^{-5} \mathrm{~cm}^{2} \mathrm{~V}^{-1} \mathrm{~S}^{-1}$ and an ON/ OFF ratio of 221 , which were comparable with those of previously reported 2D MOFs (Table S1 $\dagger$ ). Therefore, these results collectively demonstrate the potential application of 2D COMSCo in semiconducting devices.

In summary, a novel two-dimensional covalent organometallic nanosheet (COMS) was designed and successfully synthesized through the strategy of one-step conjunction of a TMT sandwich coordinate motif with $\mathrm{B}_{3} \mathrm{O}_{3}$ linkage. This facile strategy could achieve crystalline 2D COMS-Co by selfcontrolling the release of $\mathrm{Co}^{2+}$ through a one-step condensation reaction of boronic acid. The systematic characterization demonstrated the successful preparation of porous and
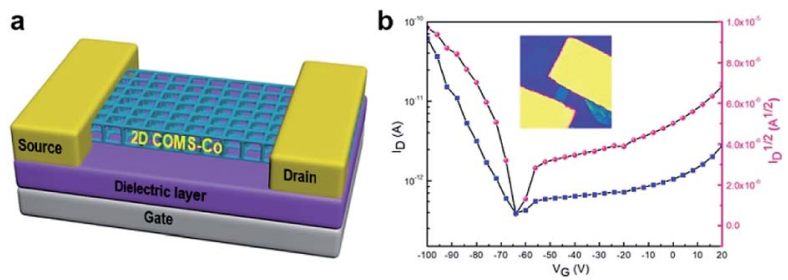

Fig. 4 (a) Schematic of the FET device employing 2D COMS-Co as the semiconducting layer. (b) Transfer curve of the 2D COMS-Co-based FET device with the inset showing an optical and model diagram of the device; $V_{G}$ is the gate-source voltage and $I_{D}$ is the drain current. crystalline 2D COMS-Co. Particularly, the as-prepared 2D COMS-Co-based FET device presented hole mobility of $5.7 \times$ $10^{-5} \mathrm{~cm}^{2} \mathrm{~V}^{-1} \mathrm{~S}^{-1}$ and an ON/OFF ratio of 221 , which demonstrated the potential application of 2D COMS-Co in semiconducting devices. Therefore, we envision that this work will open a new avenue for the synthesis of two-dimensional semiconducting covalent organometallic materials by using covalence and coordination dual synergistic connection effects via a one-step facile strategy.

\section{Conflicts of interest}

There are no conflicts to declare.

\section{Acknowledgements}

The research was supported by the National Natural Science Foundation of China (Project No. 51772110, No. 51572094 and No. 51873160). All authors are grateful for characterization and computing service from the Analytical and Testing Center of HUST and the Wuhan National Laboratory for Optoelectronics, respectively.

\section{Notes and references}

1 A. J. Clough, J. W. Yoo, M. H. Mecklenburg and S. C. Marinescu, J. Am. Chem. Soc., 2015, 137, 118-121.

2 R. Dong, M. Pfeffermann, H. Liang, Z. Zheng, X. Zhu, J. Zhang and X. L. Feng, Angew. Chem., Int. Ed., 2015, 54, 12058-12063.

3 E. M. Miner, T. Fukushima, D. Sheberla, L. Sun, Y. Surendranath and M. Dinca, Nat. Commun., 2016, 7, 10942-10948.

4 R. Sakamoto, T. Yagi, K. Hoshiko, S. Kusaka, R. Matsuoka, H. Maeda, Z. Liu, Q. Liu, W. Y. Wong and H. Nishihara, Angew. Chem., Int. Ed., 2017, 56, 3526-3530.

5 T. Kambe, R. Sakamoto, T. Kusamoto, T. Pal, N. Fu-kui, T. Shimojima, Z. Wang, T. Hirahara, K. Ishizaka, S. Hasegawa, F. Liu and H. Nishihara, J. Am. Chem. Soc., 2014, 136, 14357-14360.

6 R. Makiura, S. Motoyama, Y. Umemura, H. Yama-naka, O. Sakata and K. Hiroshi, Nat. Mater., 2010, 9, 565-571.

7 R. H. Dong, P. Han, H. Arora, M. Ballabio, M. Kara-kus, Z. Zhang, C. Shekhar, P. Alder, P. S. Petkov, A. Erbe, S. C. B. Mannsfeld, C. Felser, T. Heine, M. Bonn, X. L. Feng and E. Cánovas, Nat. Mater., 2018, 17, 1027-1032.

8 H. Sahabudeen, H. Y. Qi, B. A. Glatz, D. Tranca, R. H. Dong, Y. Hou, T. Zhang, C. Kuttner, T. Lehnert, G. Seifert, U. Kaiser, A. Fery, Z. K. Zheng and X. L. Feng, Nat. Commun., 2016, 7, 13461-13468.

9 T. Kambe, R. Sakamoto, K. Hoshiko, K. Takada, M. Miyachi, J. H. Ryu, S. Sasaki, J. Kim, K. Nakazato, M. Takata and H. Nishihara, J. Am. Chem. Soc., 2013, 135, 2462-2465.

10 Z. K. Zheng, L. Opilik, F. Schiffmann, W. Liu, G. Ber-gamini, P. Ceroni, L. T. Lee, A. Schütz, J. Sakamoto, R. Zenobi, J. VandeVondele and A. D. Schlüter, J. Am. Chem. Soc., 2014, 136, 6103-6110. 
11 R. Sakamoto, K. Hoshiko, Q. Liu, T. Yaji, T. Naga-yama, S. Kusaka, M. Tsuchiya, Y. Kitagawa, W. Y. Wong and H. Nishihara, Nat. Commun., 2015, 6, 6713-6721.

12 K. Takada, R. Sakamoto, S. T. Yi, S. Katagiri, T. Kambe and H. Nishihara, J. Am. Chem. Soc., 2015, 137, 4681-4689.

13 A. P. Côtê, A. I. Benin, N. W. Ockwig, M. O'Keeffe, A. J. Matzger and O. M. Yaghi, Science, 2005, 310, 1166-1170.

14 C. J. Doonan, D. J. Tranchemontagne, T. G. Glover, J. R. Hunt and O. M. Yaghi, Nat. Chem., 2010, 2, 235-238.

15 X. Feng, L. L. Liu, Y. Honsho, A. Saeki, S. Seki, S. Irle, Y. P. Dong, A. Nagai and D. L. Jiang, Angew. Chem., Int. Ed., 2012, 51, 2618-2622.

16 X. S. Ding, X. Feng, A. Saeki, S. Seki, A. Nagai and D. L. Jiang, Chem. Commun., 2012, 48, 8952-8954.

17 T. Tsukamoto, K. Takada, R. Sakamoto, R. Mat-suoka, R. Toyoda, H. Maeda, T. Yagi, M. Nishikawa, N. Shinjo, S. Amano, T. Iokawa, N. Ishibashi, T. Oi, K. Kanayama, R. Kinugawa, Y. Koda, T. Komu-ra, S. H. Nakajima, R. Fukuyama, N. Fuse, M. Mizui, M. Miyasaki,
Y. Yamashita, K. Yamada, W. X. Zhang, R. C. Han, W. Y. Liu, T. Tsubomura and H. Nishi-hara, J. Am. Chem. Soc., 2017, 139, 5359-5366.

18 C. P. Yang, Y. X. Yin, T. G. Guo and L. J. Wan, J. Am. Chem. Soc., 2015, 137, 2215-2218.

19 Z. A. Ghazi, L. Y. Zhu, H. Wang, A. Naeem, A. M. Khattak, B. Liang, N. A. Khan, X. Wei, L. S. Li and Z. Y. Tang, Adv. Energy Mater., 2016, 6, 1601250-1601255.

20 J. R. Hunt, C. J. Doonan, J. D. LeVangie, A. P. Côtê and O. M. Yaghi, J. Am. Chem. Soc., 2008, 130, 11872-11873.

21 H. M. EI-Kaderi, J. R. Hunt, J. L. Mendoza-Cortes, A. P. Côtê, R. E. Taylor, M. O'Keeffe and O. M. Yaghi, Science, 2007, 316, 268-272.

22 F. J. Uribe-Romo, J. R. Hunt, H. Furukawa, C. Klöck, M. O'Keeffe and O. M. Yaghi, J. Am. Chem. Soc., 2009, 131, 4570-4571.

23 J. J. Liu, W. Zan, K. Li, Y. Yang, F. X. Bu and Y. X. Xu, J. Am. Chem. Soc., 2017, 139, 11666-11669. 